It is to remedy this lack of knowledge and to marshal a host of facts in readable form that Major Coleman-Cooke has written this excellent book. In just over two hundred pages he deals with the first use of DDT against malaria, the agricultural revolution in Britain, and the first public alert following the fox disease in 1959 and the poisoning of pigeons, game and other birds from seed dressings. He follows through the implications of chemical farming from the thin layer of soil on which all life depends to the processed food we eat. A series of valuable tables shows the toxic doses of all the most widely used chemicals, and he describes the work of the various Government Committees and other bodies concerned with the problem-the latest research shows that even the seas round our coasts are contaminated and that the rate of contamination is still increasing. Noone concerned with these great issues should be without the information in this book, which is admirably prefaced by Sir Solly Zuckerman's address to the Association of British Manufacturers of Agricultural Chemicals.

C. FLOYD.

\title{
Public Relations in Natural Resources Management, by Douglas L. Gilbert. Burgess Publishing Co., Minneapolis, $\$ 2.40$.
}

Young biologists who embark on a career in conservation expect to spend most of their time working with wildlife; they may soon find that more of their time is spent working with people. This remark by Thomas L. Kimball, of the National Wildlife Federation in his Foreword to this book underlines its value.

The author, who is Associate Professor of Wildlife Managament in the Colorado State University discusses the application of modern techniques of communication in the field of nature conservation, where the understanding of an informed public is vital if the natural resources of the earth are to be managed in a spirit of trusteeship, and he has tackled his task with much zest. The history of public relations, modern methods of gaining the confidence and goodwill of sportsmen, farmers and other land usersfor there is no such thing as 'the public', but rather a host of different publics-the value of press articles, advertising, lectures, films, radio and television, all are briefly discussed in the light of experience gleaned in the United States. Some of the lessons he has mastered are relevant to the situation in Britain.

There are times when this well-documented book seems to labour the obvious. Yet no harm is done by repeating that people should be treated with courtesy and respect, that undue secrecy arouses suspicion, that dissension among naturalists may damage the image of the conservation movement, or that the chairman of natural history organisations should not emulate one who introduced the author with the words "Some guy from the Forest Service is here to show us a film about something."

\section{GARTH CHRISTIAN.}

\section{The Birds of the Palaearctic Fauna, by Charles Vaurie. Witherby, 12 gns. (Vol. 1, 5 gns.; Vol. 2, 7 gns.).}

The second and concluding volume of Charles Vaurie's invaluable synoptic survey of the Palaearctic avifauna has now been published. Volume 1 , which appeared in 1959, dealt with the great order of Passeriformes, the perohing or song birds. This volume covers all other orders of birds, from the ostriches to the woodpeckers. The information given is for each species and subspecies of its synonymy, habitat and range, both within and without the Palaearotic region, which of course includes North Africa. The first volume when it appeared immediately replaced Dresser's Manual of Palaearctic Birds, now over 60 years old, as the standard work on the 